\title{
Changes in physical activity during the retirement transition: a series of novel n-of- 1 natural experiments
}

\author{
Suzanne McDonald ${ }^{1 *}$ (D), Rute Vieira ${ }^{1}$, Alan Godfrey ${ }^{2}$, Nicola O'Brien ${ }^{1}$, Martin White ${ }^{3}$ and Falko F. Sniehotta ${ }^{1,4}$
}

\begin{abstract}
Background: Existing evidence about the impact of retirement on physical activity (PA) has primarily focused on the average change in PA level after retirement in group-based studies. It is unclear whether findings regarding the direction of PA change after retirement from group-based studies apply to individuals. This study aimed to explore changes in PA, PA determinants and their inter-relationships during the retirement transition at the individual level.

Methods: A series of n-of-1 natural experiments were conducted with seven individuals who were aged 5576 years and approaching retirement. PA was measured by tri-axial accelerometry. Twice-daily self-report and ecological momentary assessments of evidence- and theory-based determinants of PA (e.g. sleep length/ quality, happiness, tiredness, stress, time pressure, pain, intention, perceived behavioural control, priority, goal conflict and goal facilitation) were collected via a questionnaire for a period of between 3 and 7 months, which included time before and after the participant's retirement date. A personalised PA determinant was also identified by each participant and measured daily for the duration of the study. Dynamic regression models for discrete time binary data were used to analyse data for each individual participant.
\end{abstract}

Results: Two participants showed a statistically significant increase in the probability of engaging in PA bouts after retirement and two participants showed a significant time trend for a decrease and increase in PA bouts over time during the pre- to post-retirement period, respectively. There was no statistically significant change in PA after retirement for the remaining participants. Most of the daily questionnaire variables were significantly associated with PA for one or more participants but there were no consistent pattern of PA predictors across participants. For some participants, the relationship between questionnaire variables and PA changed from pre- to post-retirement.

Conclusions: The findings from this study demonstrate the impact of retirement on individual PA trajectories. Using n-of-1 methods can provide information about unique patterns and determinants of individual behaviour over time, which has been obscured in previous research. N-of-1 methods can be used as a tool to inform personalised PA interventions for individuals within the retirement transition.

Keywords: N-of-1 methods, Physical activity, Retirement, Older adults

\footnotetext{
* Correspondence: suzanne.mcdonald@ncl.ac.uk

${ }^{1}$ Institute of Health \& Society, Newcastle University, Baddiley-Clark Building,

Richardson Road, Newcastle upon Tyne NE2 4AX, UK

Full list of author information is available at the end of the article
} 


\section{Background}

Physical activity (PA) is an independent risk factor for several chronic diseases such as diabetes, cardiovascular disease and cancer [1]. Therefore, it is recommended that adults engage in at least $150 \mathrm{~min}$ of moderatevigorous PA per week, accumulated by engaging in bouts lasting at least $10 \mathrm{~min}$ in duration [1]. These PA guidelines apply to adults of all ages. However, a large proportion of adults in the UK, aged 60 years and over, do not meet these PA levels [2]. Encouraging older adults to increase PA is a key public health challenge.

The retirement transition may represent an opportunity to promote healthier behaviours and habits that persist into older adulthood [3-5]. Previous studies have shown that PA levels change in response to retirement but findings are inconsistent regarding the direction and magnitude of PA change, with some studies showing that PA levels increase $[6,7]$ and others showing PA levels decrease $[8,9]$ after retirement. Pre-retirement occupation type (i.e. manual vs. non-manual) has been suggested as a potential moderator $[10,11]$. In other words, individuals retiring from physically demanding occupations may experience a net decrease in PA, whereas those retiring from sedentary occupations may experience changes in the opposite direction after leaving work. However, recent studies do not support this hypothesis [12].

Several other factors may determine the magnitude and direction of PA change after retirement, but only a limited number of potential PA determinants have been studied $[13,14]$. Findings from qualitative research show that individuals approaching retirement and those who have recently retired believe that a wide range of factors influence their PA after retirement $[13,15]$. For example, individuals report that there is more time availability, energy and motivation for engaging in PA after retirement, and new social roles and opportunities arise, which may either facilitate or conflict with engaging in PA [15]. Retirement has also been associated with changes in sleep length/quality, mood, fatigue and stress [16-18], which are factors commonly reported as determinants of PA [19]. PA levels and determinants are perceived to be dynamic in nature and may change several times during the first few years of retirement $[15,20]$.

Understanding changes in PA levels and determinants during the retirement transition is essential for designing effective interventions targeting this period. Due to the multiple inter-related changes that may take place during the retirement transition, individual PA trajectories may vary considerably. However, most existing evidence about PA change after retirement has been derived from longitudinal or cross-sectional studies that tend to focus on the average change in PA, obscuring individual PA trajectories. Furthermore, longitudinal studies typically involve few (self-reported) measurements of PA, which provides limited information about PA change over time $[14,21]$. Research methods that capture intra-individual change and variability in PA, and determinants thereof, may add a crucial perspective.

$\mathrm{N}$-of-1 methods involve the repeated measurement of an individual over time allowing conclusions to be drawn about the individual. They are emerging as a viable research method in health behaviour research [22, 23] and have been previously applied to study PA [24, $25]$. The aim of this study was to use n-of- 1 methods to explore whether PA, PA determinants and their interrelationships change during the retirement transition within individuals.

\section{Method \\ Design}

A series of n-of-1 natural experiments were conducted in participants' natural environment. Retirement represented a naturally occurring 'intervention'. Data were collected from participants on a daily basis for a minimum of 2 months (up to a maximum of 7 months) covering a period pre- and post-retirement (at least 1 month pre- and 1 month post-retirement). The length of the study period was based on participant willingness to extend participation beyond the minimum 2-month period.

\section{Participants}

Individuals who were in full- or part-time employment and had a planned date of retirement within the subsequent 6 months were eligible to participate. Participants were recruited via study advertisements placed in the community and sent to charity organisations in Newcastle upon Tyne, UK. Although retirement was selfdefined by the participant, individuals retiring from fulltime to part-time employment were eligible to participate only if working hours were reduced by at least $50 \%$. The study was approved by Newcastle University's Medical Sciences Ethics Committee (00630_1/2013).

\section{Measures \\ Initial meeting}

Each participant completed a demographic questionnaire. Participants' home postcodes were collected and entered into the database from the Office for National Statistics website (www.ons.gov.uk) to obtain an index of multiple deprivation (IMD) score [26], which was used as an indicator of socio-economic status. Typical levels of occupation-related PA over the previous year were collected via the EPIC PA questionnaire [27]. A semistructured interview was conducted with each participant to elicit views about anticipated PA change after retirement and the determinants of their own PA. 
Responses were used to formulate personalised questionnaire items for inclusion in the daily measures.

\section{Daily measures}

PA data were collected at 60-min epochs during a period pre- to post-retirement using wrist-worn PRO-Diary devices (CamNtech, Ltd.; Cambridge, UK) designed to collect objectively-measured tri-axial accelerometry data and self-reported questionnaire data. During the study period, participants were prompted to complete a brief questionnaire displayed on the PRO-Diary in the morning and evening. Two audible prompts occurred at a time selected by each participant during their initial meeting with the researcher. Participants then responded to questions on a visual analogue scale with anchors appropriate to each item. The morning questionnaire included 10 items; the first two items collected data about the number of hours and quality of sleep the participant had the previous night. The remaining items were ecological momentary assessments (EMA) of happiness, tiredness, stress, time pressure, pain, intention, perceived behavioural control $(\mathrm{PBC})$ and priority to engage in PA. The evening questionnaire included two items that measured whether other daily activities or goals had conflicted with or facilitated engaging in PA [28] and a personalised item, which was formulated at the initial meeting (see Additional file 1 for questionnaire items). Participants were asked an additional three questions in the morning and an additional two questions in the evening that were related to sedentary behaviour and are not reported here.

\section{Procedure}

\section{Initial meeting}

Participants provided written consent, completed questionnaires and received a demonstration of the PRODiary. PA bouts were the study outcome of interest. PA was defined to participants as any type of PA that lasted at least 10 consecutive minutes.

\section{Data collection period}

Participants were contacted via email/telephone each week to check for potential problems and met a researcher face-to-face on a monthly basis to receive a fully-charged PRO-Diary for the subsequent month of data collection. Participants did not receive feedback about their data during the study. Daily data were collected for a minimum of 2 months. Participants were invited to extend their participation (up to a maximum of six additional months). Depending on the participant's retirement date, this involved further data collection in the pre- and/or post-retirement period. Participants received a $£ 10$ (\$12.44) gift voucher at each monthly meeting to reimburse participation.

\section{Post-study feedback}

Participants were given personalised oral and written feedback about their PA over the study period (e.g. PA levels and PA predictors). The participant's graphed data were used to stimulate discussion and interpretations with the participant. A semi-structured interview was conducted to elicit views about the acceptability of participating in an n-of-1 study (data are not presented here).

\section{Data analyses \\ Data processing}

Minute-by-minute PA data were downloaded from the PRO-Diary device and combined into one file for each participant. The number of PA bouts performed per day was calculated using an automated algorithm (available upon request from the authors). At the initial meeting, participants chose on which wrist they would prefer to wear the PRO-Diary. The participant wore the device on the same wrist for the duration of the study. PA data were interpreted based on cut-points which defined when the participant was performing PA of any intensity; $\geq 215$ raw counts was used when the device was worn on the left (non-dominant) wrist and $\geq 385$ raw counts was used for the right (dominant) wrist, based on a comparable association [29] to a wrist-worn device utilised in a previous study [30]. These cut-points are equivalent to $\geq 1.5$ METS. To distinguish sleeping and awake periods, awakening was identified with five consecutive minutes of non-zero counts after 04:00 h. Sleeping was identified when there were two hours with 0 raw counts, interrupted with a maximum of three minutes of non-zero counts. As participant 7 wore the PRO-Diary overnight, sleeping was identified when there were two hours with 0 raw count, interrupted with a maximum of 10 non-consecutive minutes of non-zero counts. Missing PA data was identified when there was a string of 0 raw counts interrupted by a maximum of two minutes of PA within a 60-min period. If the participant removed the PRO-Diary for the day, sleeping time for those days was defined as the median sleeping time of all other days. Data from the moment the PRO-Diary was removed to sleeping time were considered missing data. Missing questionnaire data were identified and imputed using the average value of the three previous and three subsequent days.

\section{Statistical analysis}

PA was considered as longitudinal binary data (i.e. PA or no PA) measured each minute during the study period. Dynamic regression models [31] for discrete time binary data were used to express and model each participant's PA behaviour over time. Time $(t)$ was assumed to be a discrete variable such that $t=0,1, \ldots \mathrm{T}$, where $\mathrm{T}$ is the 
total number of minutes of awake time for the participant. The observations of PA bouts $(\mathrm{Y})$ form a subjectspecific binary process $Y_{1}, \ldots, Y_{T}$, where $Y_{t}=1$ if the participant initiates a PA bout at minute $t, \mathrm{Y}_{\mathrm{t}}=0$ otherwise.

The dynamic regression modelling procedure used in this study has been described in detail elsewhere [32]. Briefly, two sets of covariates, $X_{t}$ and $D_{t}$, which vary over time are considered. The first, $X_{t}$, describes exogenous variables such as trend over time, day of the week (weekend, workday), period of the day (morning: waking time12:00, afternoon: 12:00-18:00, evening: 18:00-sleep time; with afternoon used as the reference variable) together with endogenous variables such as retirement period (pre-retirement, post-retirement) and predictor variables from the morning and evening questionnaire (scale: $0.0-$ 1.0). The second, $D_{t}$, are dynamic covariates constructed to summarise the history up to $t$ of responses $\mathrm{Y}_{1}, \ldots, \mathrm{Y}_{\mathrm{t}}$ for the individual. The number of PA bouts in the previous two hours was selected to account for autocorrelation (i.e. dependency between the data points due to repeated measurements from the same individual) between consecutive PA bouts while the number of PA bouts $d$ days earlier for $d=1,2$ adjusts for the effect of the amount of exercise done in the two previous days. Other dynamic variables included questionnaire variables for one (lag 1 ) and 2 days prior (lag 2). Independence of data points is assumed, as the conditional distributions given earlier responses are modelled.

Descriptive, univariate and multivariate analyses were performed. As the number of potential predictors was large and it was of interest to determine the most influential variables, a stepwise strategy was used to select the best fitting multivariate model according to Akaike's Information Criterion. Retirement period, as well as time, weekday, period of day, number of bouts in last $2 \mathrm{~h}$ and number of bouts in the previous day/two days were forced into the model regardless of significance for each participant to control for any existing time trend, periodicity or autocorrelation. Potential interactions between retirement period and other exogenous/endogenous variables were explored by including the interaction terms in the stepwise process. Global goodness-of-fit was assessed with the Hosmer and Lemeshow test [33]. Multicollinearity was assessed using variation inflation factors for the predictors included in the final model. Data were analysed for each participant individually using R 3.2.3. The significance level was set at $p<0.05$.

\section{Results}

\section{Participant characteristics}

Table 1 displays participant characteristics. Seven righthanded individuals (five female) aged 55-76 years who were approaching retirement responded to advertisements and provided written informed consent to
Table 1 Characteristics of the seven participants

\begin{tabular}{|c|c|c|c|c|c|c|}
\hline Participant & Sex & Age & $\begin{array}{l}\text { Marital } \\
\text { status }\end{array}$ & Occupation $^{a}$ & Retirement & $\begin{array}{l}\mathrm{IMD}^{\mathrm{b}} \\
\text { score }\end{array}$ \\
\hline 1 & Female & 65 & Married & $\begin{array}{l}\text { Librarian } \\
\text { (FT) }\end{array}$ & $\begin{array}{l}\text { Full } \\
\text { retirement }\end{array}$ & 10 \\
\hline 2 & Female & 76 & Widowed & $\begin{array}{c}\text { Shop owner } \\
\text { (PT) }\end{array}$ & $\begin{array}{c}\text { Full } \\
\text { retirement }\end{array}$ & 7 \\
\hline 3 & Male & 56 & Married & $\begin{array}{l}\text { Civil servant } \\
(\mathrm{FT})\end{array}$ & $\begin{array}{c}\text { Full } \\
\text { retirement }\end{array}$ & 6 \\
\hline 4 & Male & 60 & Married & $\begin{array}{l}\text { HR manager } \\
(\mathrm{FT})\end{array}$ & $\begin{array}{c}\text { Full } \\
\text { retirement }\end{array}$ & 9 \\
\hline 5 & Female & 64 & Married & $\begin{array}{l}\text { Secretary } \\
(\mathrm{PT})\end{array}$ & $\begin{array}{c}\text { Full } \\
\text { retirement }\end{array}$ & 3 \\
\hline 6 & Female & 55 & Married & Nurse (FT) & $\begin{array}{c}\text { Full } \\
\text { retirement }\end{array}$ & 10 \\
\hline 7 & Female & 63 & Divorced & Nurse (FT) & $\begin{array}{l}\text { Part time } \\
\text { work }^{c}\end{array}$ & 9 \\
\hline
\end{tabular}

${ }^{\mathrm{a}} \mathrm{FT}=$ full time ( $\geq 35 \mathrm{~h}$ per week); $\mathrm{PT}=$ part time $(<35 \mathrm{~h}$ per week $)$

${ }^{\mathrm{b}} \mathrm{IMD}=$ Index of multiple deprivation

${ }^{\mathrm{C}}$ Working hours reduced from 37.5 per week to $16 \mathrm{~h}$ per week

participate. Only one participant (participant 7) wore the PRO-Diary on the right (dominant) wrist, therefore, higher cut-point values were used for this participant [30]. All participants reported their pre-retirement occupation within the 'sedentary' classification on the EPIC physical activity questionnaire [27], except participant 2 who reported their occupation within the 'standing' classification. All participants agreed to extend their participation beyond the initial 2-month study period and provided daily data for between 3 and 7 months. The total number of study days ranged from 87 (participant 6), to 196 (participants 3 and 4) days.

\section{Descriptive statistics}

Participant 5 had the highest amount of missing (nonwear) PA data during awake periods (4.2\%) while participant 1 wore the accelerometer throughout all awake periods. The median amount of hours awake per day for each participant ranged from 13.6 to 16.3. A method of data imputation was not used for PA data since missing PA data were minimal (Additional file 2 displays further details about awake/non-wear time per participant).

The median number of daily PA bouts ranged from 4 to 13 in the pre-retirement phase and from 5 to 15 in the post-retirement phase (see Table 2). Participant 2 experienced the highest decrease in the median number of PA bouts per day (pre-retirement: 12, postretirement: 9) while participant 3 experienced the highest increase (pre-retirement: 13, post-retirement: 15). The median number of minutes spent in a PA bout ranged from 13 to 15 in the pre-retirement phase and 13 to 17 in the post-retirement phase. Participant 1 did the least minutes of PA per day, (median: pre-retirement $57 \mathrm{~min}$; post-retirement $74 \mathrm{~min}$ ) while participant $3 \mathrm{did}$ 
Table 2 Descriptive statistics for the number of PA bouts and number of minutes in PA bouts for each participant pre- and postretirement

\begin{tabular}{|c|c|c|c|c|c|c|c|c|c|}
\hline \multicolumn{8}{|c|}{ No. of PA bouts } & \multicolumn{2}{|c|}{ No. of minutes in PA bouts } \\
\hline \multirow[b]{2}{*}{ Participant } & \multirow{2}{*}{$\begin{array}{l}\text { All day } \\
\text { Per day }\end{array}$} & \multicolumn{2}{|c|}{ Morning } & \multicolumn{2}{|c|}{ Afternoon } & \multicolumn{2}{|c|}{ Evening } & \multirow[b]{2}{*}{ Per bout ${ }^{a}$} & \multirow[b]{2}{*}{ Per day ${ }^{a}$} \\
\hline & & Per day ${ }^{a}$ & Total $^{b}$ & Per day ${ }^{a}$ & Total $^{\mathrm{b}}$ & Per day ${ }^{a}$ & Total $^{b}$ & & \\
\hline \multicolumn{10}{|l|}{1} \\
\hline Pre & $4(1,12)$ & $1(0,6)$ & $66(32.8)$ & $2(0,7)$ & $93(46.3)$ & $1(0,6)$ & $42(20.9)$ & $13(10,51)$ & $57(12,213)$ \\
\hline Post & $5(1,14)$ & $1(0,8)$ & $159(38.2)$ & $2(0,10)$ & $196(47.1)$ & $0(0,4)$ & $61(14.7)$ & $13(10,99)$ & $74(10,279)$ \\
\hline \multicolumn{10}{|l|}{2} \\
\hline Pre & $12(3,24)$ & $2(0,6)$ & $403(36.0)$ & $4(0,10)$ & $522(46.6)$ & $1(0,6)$ & $196(17.5)$ & $15(10,81)$ & $204(50,431)$ \\
\hline Post & $9(3,21)$ & $5(1,9)$ & $357(41.1)$ & $5(1,11)$ & $365(42.1)$ & $2(0,6)$ & $146(16.8)$ & $14(10,71)$ & $146(34,348)$ \\
\hline \multicolumn{10}{|l|}{3} \\
\hline Pre & $13(3,24)$ & $4(1,11)$ & $385(38.8)$ & $5(0,12)$ & $366(36.9)$ & $3(0,7)$ & $240(24.2)$ & $15(10,124)$ & $239(42,514)$ \\
\hline Post & $15(3,26)$ & $6(0,11)$ & $671(40.7)$ & $5(0,11)$ & $656(39.8)$ & $3(0,7)$ & $323(19.6)$ & $17(10,133)$ & $303(67,571)$ \\
\hline \multicolumn{10}{|l|}{4} \\
\hline Pre & $7(2,16)$ & $2(0,7)$ & $244(35.3)$ & $3(0,10)$ & $308(44.6)$ & $1(0,6)$ & $139(20.1)$ & $15(10,176)$ & $127(31,330)$ \\
\hline Post & $8(3,18)$ & $4(0,8)$ & 383 (41.9) & $4(0,10)$ & $411(45.0)$ & $1(0,5)$ & $120(13.1)$ & $15(10,150)$ & $145(37,411)$ \\
\hline \multicolumn{10}{|l|}{5} \\
\hline Pre & $11(3,19)$ & $4(0,9)$ & 168 (33.6) & $4(1,9)$ & $201(40.2)$ & $3(0,8)$ & $131(26.2)$ & $15(10,90)$ & $197(68,480)$ \\
\hline Post & $10.5(3,21)$ & $3(0,9)$ & $249(29.4)$ & $5(0,10)$ & $389(45.9)$ & $2(0,10)$ & $210(24.8)$ & $15(10,100)$ & $184(40,426)$ \\
\hline \multicolumn{10}{|l|}{6} \\
\hline Pre & $8(2,14)$ & $2(0,7)$ & 83 (31.8) & $3(0,9)$ & $117(44.8)$ & $2(0,5)$ & $61(23.4)$ & $15(10,85)$ & $131(29,262)$ \\
\hline Post & $9(2,16)$ & $2(0,6)$ & $121(24.6)$ & $5(0,10)$ & $237(48.3)$ & $2(0,10)$ & $133(27.1)$ & $15(10,108)$ & $173(31,463)$ \\
\hline \multicolumn{10}{|l|}{7} \\
\hline Pre & $7.5(4,19)$ & $3(0,9)$ & $120(39.6)$ & $3(0,9)$ & $124(40.9)$ & $1(0,6)$ & 59 (19.5) & $14(10,48)$ & $126(55,296)$ \\
\hline Post & $7(0,20)$ & $2(0,7)$ & $372(40.0)$ & $3(0,12)$ & 409 (42.9) & $1(0,5)$ & $173(18.1)$ & $13(10,60)$ & $101(0,365)$ \\
\hline
\end{tabular}

${ }^{a}$ Reporting: median (range)

${ }^{\mathrm{b}}$ Reporting: $\mathrm{n}(\%)$

the most (median: pre-retirement $239 \mathrm{~min}$; postretirement $303 \mathrm{~min}$ ).

Missing questionnaire data ranged from 3.4 to $8.6 \%$. Visual inspection of the data for each participant indicated that missing data did not occur systematically (e.g. according to the day of the week). Tables 3 and 4 summarise daily questionnaire data. The median length of self-reported sleep for pre-retirement and postretirement ranged between 6 and $8.5 \mathrm{~h}$. The median number of hours of sleep pre- and post-retirement appeared to be similar for most participants, with $0.5 \mathrm{~h}$ increase and decrease for participants 6 and 1 , respectively. In relation to sleep quality, participant 6 had the lowest median scores (pre-retirement: 0.4 ; postretirement: 0.6) while participant 3 had the highest median scores (pre-retirement: 1.0; post-retirement: 1.0). The median sleep quality score increased postretirement for all participants except participant 3 and 7. The median score for happiness, PA intention and PA facilitation increased or stayed the same post-retirement for all participants, whereas the median score for stress, time pressure and PA conflict decreased or stayed the same post-retirement for all participants. The median score for tiredness decreased post-retirement, except for participants 5 and 7, where the median tiredness score increased, and for participant 3, where the median tiredness score stayed the same. For all participants the median PA PBC score decreased post-retirement and the median PA priority score increased post-retirement. For participants 1, 4, 6 and 7 the median score on their personalised item decreased post-retirement, whereas for participant 5 it increased and for participants 2 and 3 it stayed the same post-retirement.

\section{Dynamic regression results}

The analysis was performed using awake data only. Table 5 describes the multivariable results for each participant (see Additional file 3 for detailed multivariable models for each participant).

\section{Does PA change from pre- to post-retirement?}

There was a statistically significant increase in the probability of engaging in PA bouts for participants 4 and 7 pre- to post-retirement $(p=0.03$ and $p=0.001)$, with 
Table 3 Descriptive statistics for the morning questionnaire data for each participant pre- and post-retirement ${ }^{a}$

\begin{tabular}{|c|c|c|c|c|c|c|c|c|c|c|}
\hline Participant & Sleep length & Sleep quality & Happiness & Tiredness & Stress & Time pressure & Pain & PA intention & PBC & PA priority \\
\hline \multicolumn{11}{|l|}{1} \\
\hline Pre & $7.5(3.5,9.5)$ & $0.7(0.1,0.9)$ & $0.8(0.4,0.9)$ & $0.4(0.1,0.8)$ & $0.2(0.0,0.9)$ & $0.3(0.0,0.8)$ & $0.7(0.3,0.8)$ & $0.6(0.3,0.8)$ & $0.5(0.2,0.8)$ & $0.4(0.3,0.9)$ \\
\hline Post & $7.0(5.0,9.0)$ & $0.8(0.6,0.9)$ & $0.8(0.5,1.0)$ & $0.3(0.1,0.8)$ & $0.2(0.0,0.6)$ & $0.2(0.0,0.6)$ & $0.6(0.5,0.8)$ & $0.7(0.3,0.8)$ & $0.3(0.1,0.8)$ & $0.5(0.3,0.7)$ \\
\hline \multicolumn{11}{|l|}{2} \\
\hline Pre & $8.5(7.0,9.5)$ & $0.8(9.3,1.0)$ & $0.7(0.1,0.9)$ & $0.3(0.1,0.6)$ & $0.4(0.1,0.8)$ & $0.3(0.0,0.8)$ & $0.0(0.0,0.5)$ & $0.6(0.2,0.9)$ & $0.5(0.2,0.8)$ & $0.6(0.3,0.8)$ \\
\hline Post & $8.5(5.5,10.5)$ & $0.9(0.3,0.9)$ & $0.8(0.1,0.9)$ & $0.2(0.1,1.0)$ & $0.2(0.1,0.7)$ & $0.2(0.0,0.8)$ & $0.0(0.0,0.9)$ & $0.7(0.1,0.9)$ & $0.2(0.1,0.9)$ & $0.7(0.2,0.9$ \\
\hline \multicolumn{11}{|l|}{3} \\
\hline Pre & $6.0(3.0,7.5)$ & $1.0(0.0,1.0)$ & $1.0(0.1,1.0)$ & $0.4(0.0,1.0)$ & $0.0(0.0,0.9)$ & $0.0(0.0,1.0)$ & $0.0(0.0,0.9)$ & $0.4(0.0,1.0)$ & $0.8(0.0,1.0)$ & $0.3(0.0,1.0)$ \\
\hline Post & $6.0(3.0,7.5)$ & $1.0(0.0,1.0)$ & $1.0(0.2,1.0)$ & $0.4(0.0,1.0)$ & $0.0(0.0,0.8)$ & $0.0(0.0,1.0)$ & $0.0(0.0,0.8)$ & $0.6(0.5,1.0)$ & $0.5(0.0,1.0)$ & $0.6(0.0,1.0)$ \\
\hline \multicolumn{11}{|l|}{4} \\
\hline Pre & $7.0(4.0,9.0)$ & $0.7(0.2,0.9)$ & $0.8(0.3,0.9)$ & $0.7(0.1,1.0)$ & $0.2(0.0,0.7)$ & $0.6(0.0,0.8)$ & $0.1(0.0,0.7)$ & $0.6(0.1,1.0)$ & $0.6(0.0,0.9)$ & $0.3(0.1,1.0)$ \\
\hline Post & $7.0(3.5,8.5)$ & $0.8(0.0,1.0)$ & $0.9(0.6,1.0)$ & $0.3(0.0,0.9)$ & $0.1(0.0,1.0)$ & $0.2(0.0,0.9)$ & $0.2(0.0,0.8)$ & $0.6(0.1,0.9)$ & $0.2(0.1,0.9)$ & $0.5(0.1,0.9)$ \\
\hline \multicolumn{11}{|l|}{5} \\
\hline Pre & $6.0(5.0,7.0)$ & $0.8(0.4,0.9)$ & $1.0(0.1,1.0)$ & $0.1(0.0,0.6)$ & $0.1(0.0,0.8)$ & $0.6(0.0,0.9)$ & $0.0(0.0,0.0)$ & $0.4(0.1,0.9)$ & $0.8(0.2,0.9)$ & $0.3(0.1,0.8)$ \\
\hline Post & $6.0(5.0,7.0)$ & $0.9(0.2,1.0)$ & $1.0(0.5,1.0)$ & $0.3(0.0,0.9)$ & $0.0(0.0,0.1)$ & $0.0(0.0,0.8)$ & $0.1(0.0,0.3)$ & $0.7(0.2,0.9)$ & $0.4(0.1,1.0)$ & $0.6(0.1,0.8)$ \\
\hline \multicolumn{11}{|l|}{6} \\
\hline Pre & $7.0(5.0,8.0)$ & $0.4(0.0,1.0)$ & $0.6(0.2,0.8)$ & $0.8(0.2,1.0)$ & $0.5(0.2,1.0)$ & $0.7(0.0,1.0)$ & $0.2(0.1,0.6)$ & $0.2(0.0,0.9)$ & $0.8(0.1,1.0)$ & $0.4(0.0,0.8)$ \\
\hline Post & $7.5(6.0,8.5)$ & $0.6(0.0,0.9)$ & $0.8(0.4,1.0)$ & $0.4(0.1,1.0)$ & $0.0(0.0,0.3)$ & $0.1(0.0,0.7)$ & $0.2(0.1,0.3)$ & $0.9(0.1,1.0)$ & $0.2(0.0,1.0)$ & $0.8(0.0,1.0)$ \\
\hline \multicolumn{11}{|l|}{7} \\
\hline Pre & $6.3(4.0,8.5)$ & $0.8(0.2,1.0)$ & $0.5(0.3,0.7)$ & $0.2(0.0,0.7)$ & $0.2(0.0,0.5)$ & $0.2(0.0,0.7)$ & $0.6(0.4,1.0)$ & $0.4(0.2,0.6)$ & $0.7(0.3,0.9)$ & $0.4(0.1,0.9)$ \\
\hline Post & $6.0(4.0,9.0)$ & $0.7(0.6,0.9)$ & $0.5(0.2,0.9)$ & $0.4(0.0,0.8)$ & $0.2(0.0,1.0)$ & $0.1(0.0,0.6)$ & $0.4(0.0,0.8)$ & $0.5(0.2,1.0)$ & $0.5(0.1,0.9)$ & $0.5(0.2,0.8)$ \\
\hline
\end{tabular}

$\mathrm{PBC}=$ perceived behavioural control

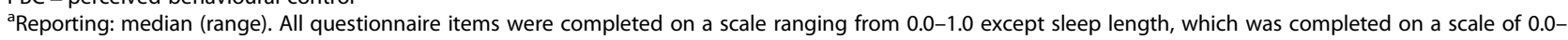
12.0 and had an interval of 0.5 units. A higher score indicated higher rating (e.g. better sleep quality, more hours of sleep) apart from PBC, where a higher score indicated higher perceived difficulty (i.e. less perceived behavioural control) to engage in PA

participant 7 also showing an increase of PA over time $(p$ $=0.017$ ). Participant 2 showed a statistically significant time trend for decreased probability of engaging in PA bouts over the study period $(p<0.001)$ and participant 5 showed a statistically significant time trend for increased probability of engaging in PA bouts over the study period $(p=0.019)$.

\section{What are the predictors of PA bouts?}

Participant 3 was less likely to engage in PA bouts at weekends $(p<0.001)$. There was a decreased probability of engaging in PA bouts in the evening compared to the afternoon for all participants (all $p<0.001$ ). For participant 2 there was an increased probability of engaging in PA bouts in the morning compared to the afternoon $(p=0.002)$. There was considerable variation between participants concerning measured PA determinants on PA bouts. There was no consistent pattern of PA predictors across participants; all predictor variables (except pain) were associated with PA bouts for at least one participant. For example, sleep length was only significantly associated with engaging in PA bouts for participants 1 and 7 ( $p=0.022 ; p=0.018$, respectively) and sleep quality was only significantly associated with engaging in PA bouts for participant 1 and $6(p=0.045 ; p$ $=0.003$, respectively). For participant 1 , not only was there an increase in probability of engaging in PA bouts with more hours of sleep the previous night, but the amount of sleep accumulated 2 days before was also associated with an increase probability of engaging in PA bouts on the current day. The personalised questionnaire item was a significant predictor of PA bouts for participants 1, 4, 5 and 7. Participants 4 and 5 engaged in less PA bouts on days when they reported greater influence from their spouse/other people on their PA ( $p=$ 0.032 and $p<0.001$, respectively). Participant 1 engaged in less PA bouts on days when they reported greater spousal influence on their PA and more PA bouts on days when they reported greater spousal influence 2 days prior $(p=0.012)$. Participant 7 engaged in less PA bouts when they reported greater influence from other people on their PA 2 days prior $(p=0.003)$ and 1 day prior $(p=$ $0.005)$. For participant 2,3 and 5 , the number of PA bouts in the previous two hours was significantly associated with an increased probability of PA bouts ( $p=$ $0.002 ; p=0.018 ; p=0.039$, respectively). For two 
Table 4 Descriptive statistics for the evening questionnaire data for each participant pre- and post-retirement ${ }^{\mathrm{a}}$

\begin{tabular}{|c|c|c|c|}
\hline Participant & PA facilitation & PA conflict & PA personalised \\
\hline \multicolumn{4}{|l|}{1} \\
\hline Pre & $0.6(0.0,0.8)$ & $0.4(0.2,0.8)$ & $0.2(0.0,0.6)$ \\
\hline Post & $0.7(0.1,0.9)$ & $0.3(0.2,0.9)$ & $0.0(0.0,0.2)$ \\
\hline \multicolumn{4}{|l|}{2} \\
\hline Pre & $0.6(0.0,1.0)$ & $0.5(0.0,1.0)$ & $0.7(0.1,1.0)$ \\
\hline Post & $0.7(0.1,1.0)$ & $0.5(0.1,0.9)$ & $0.7(0.1,0.9)$ \\
\hline \multicolumn{4}{|l|}{3} \\
\hline Pre & $0.3(0.0,1.0)$ & $0.8(0.0,1.0)$ & $1.0(0.2,1.0)$ \\
\hline Post & $0.3(0.0,1.0)$ & $0.8(0.0,1.0)$ & $1.0(0.4,1.0)$ \\
\hline \multicolumn{4}{|l|}{4} \\
\hline Pre & $0.4(0.0,1.0)$ & $0.6(0.0,1.0)$ & $0.4(0.0,1.0)$ \\
\hline Post & $0.5(0.0,0.9)$ & $0.2(0.0,0.9)$ & $0.3(0.0,0.9)$ \\
\hline \multicolumn{4}{|l|}{5} \\
\hline Pre & $0.5(0.2,0.9)$ & $0.8(0.2,1.0)$ & $0.1(0.0,0.9)$ \\
\hline Post & $0.6(0.2,1.0)$ & $0.4(0.0,0.9)$ & $0.7(0.0,0.9)$ \\
\hline \multicolumn{4}{|l|}{6} \\
\hline Pre & $0.0(0.0,0.8)$ & $1.0(0.3,1.0)$ & $0.8(0.1,1.0)$ \\
\hline Post & $0.3(0.0,1.0)$ & $0.5(0.0,1.0)$ & $0.6(0.0,0.8)$ \\
\hline \multicolumn{4}{|l|}{7} \\
\hline Pre & $0.2(0.1,0.8)$ & $0.7(0.2,1.0)$ & $0.5(0.0,1.0)$ \\
\hline Post & $0.3(0.0,0.8)$ & $0.5(0.0,0.9)$ & $0.2(0.0,1.0)$ \\
\hline
\end{tabular}

${ }^{a}$ Reporting: median (range). These questions were asked at the end of the day in reference to that day

'Participant 1 answered 'How much did your husband influence your PA today?' Participant 2, 4, 6 and 7 answered 'To what extent did other people influence your PA today?' Participant 3 answered 'How would you rate your asthma symptoms today?' Participant 5 'How did seeing your partner today affect how much PA you did?'

participants, the number of PA bouts in the previous 2 days (participant 2) and previous day (participant 5) were significantly associated with an increased probability of PA bouts on the current day ( $p=0.037 ; p=0.009$, respectively).

\section{Is retirement interacting with the other predictors?}

Although the results show that retirement did not have a statistically significant effect in the probability of engaging in PA for most participants, retirement interacted with some of the predictors for all participants, except participant 5 . There was a significant interaction between period of the day and retirement status on PA bouts for participants 1,3 and 4 . In addition, higher ratings on the following variables were associated with an increased probability of PA bouts in the post-retirement period; sleep quality (participants 1 and 2; $p=0.042$ and $p=0.004$, respectively), $\mathrm{PA}$ intention (participant $3 ; p$ $=0.002$ ), $\mathrm{PA} \mathrm{PBC}$ (indicating more difficulty to engage in PA, participants 3 and $7 ; p=0.001$ and $p=0.029$, respectively), PA facilitation (participant 6; $p=0.010$ ) and PA conflict (participant $6 ; p=0.049$ ). Lower ratings on the following variables were associated with an increased probability of PA bouts in the post-retirement period; tiredness (participant 6; $p=0.040$ ), happiness (participant 3; $p=0.017$ ), stress (participants 1, 3 and 7; $p=0.004, p=0.036$ and $p=0.002$, respectively), PA intention (participant 6; $p<0.001$ ), PA PBC (indicating less difficulty to engage in PA, participant 2; $p=0.032$ ) and PA conflict (participant 7; $p=0.002$ ).

\section{Discussion \\ Main findings}

There was a significant change (i.e. increase) in the number of PA bouts performed after retirement for two of the seven participants in this study. There was no consistent pattern of PA predictors across participants; all predictor variables (except pain) were associated with PA bouts for at least one participant. However, none were associated with PA bouts for all participants. The predictors that influenced the probability of engaging in PA bouts the most for each participant were as follows: stress (participants 1 and 7); the extent to which other activities conflicted with engaging in PA (participants 2 and 5); $\mathrm{PBC}$ for engaging in PA (participant 3); happiness (participant 4) and intention to engage in PA (participant 6). For five participants, the relationship between PA determinants and PA bouts changed pre- to post-retirement.

\section{Relationship to previous research}

For most participants, there was no significant change in the number of PA bouts performed pre- to postretirement. The findings from this study are in contrast to existing evidence which show that PA levels change, either in a positive or negative direction, after retirement [11]. Previous studies have used research designs that focus on the change in PA after retirement on average in a population sample, which may have obscured individual trajectories. Due to the nature of aggregation the average PA trajectory after retirement may not represent all or any of the individuals studied [23]. Furthermore, previous studies have measured PA several years postretirement when individuals are likely to have settled into a retirement routine. As a result, these studies provide limited information about PA around the transition to retirement. This information is needed to inform interventions targeting the retirement transition, when individuals may be more receptive to interventions targeting health behaviours $[4,15]$.

This study focused on the retirement transition and found that most individuals compensate for their preretirement PA in the period immediately after they retire. However, PA at this level may not be sustained over 
Table 5 Overview table showing multivariable associations between predictor variables and PA bouts for all participants

\begin{tabular}{|c|c|c|c|c|c|c|c|c|}
\hline & & Participant 1 & Participant 2 & Participant 3 & Participant 4 & Participant 5 & Participant 6 & Participant 7 \\
\hline \multicolumn{9}{|l|}{ Variable } \\
\hline \multicolumn{9}{|l|}{ Main effects } \\
\hline Time (study day) & & -0.004 & $-0.003^{* * *}$ & 0.000 & 0.001 & $0.004^{*}$ & 0.006 & $0.017^{*}$ \\
\hline \multicolumn{9}{|l|}{ Retirement $^{\mathrm{a}}$} \\
\hline & $\begin{array}{c}\text { Post- } \\
\text { retirement }\end{array}$ & 0.204 & -0.410 & 0.057 & $1.471^{*}$ & -0.115 & 0.567 & $0.801^{* *}$ \\
\hline \multicolumn{9}{|l|}{ Day of week ${ }^{b}$} \\
\hline & Weekend & -0.111 & -0.027 & $-0.188^{* * *}$ & 0.140 & -0.004 & 0.062 & -0.021 \\
\hline \multicolumn{9}{|l|}{ Period of day ${ }^{c}$} \\
\hline & Morning & -0.128 & $0.157^{* *}$ & 0.145 & -0.050 & 0.119 & 0.061 & 0.070 \\
\hline & Evening & $-1.114^{* * *}$ & $-0.466^{* * *}$ & $-0.581^{* * *}$ & $-1.274^{* * *}$ & $-0.321^{* * *}$ & $-0.510^{* * *}$ & $-0.727^{* * *}$ \\
\hline \multirow[t]{2}{*}{ Sleep length } & & $\begin{array}{l}\mathbf{0 . 1 2 7 *} \\
(\operatorname{lag} 0)\end{array}$ & - & - & - & - & - & $\begin{array}{l}\mathbf{0 . 0 9 9 ^ { * }} \\
(\operatorname{lag} 0)\end{array}$ \\
\hline & & $\begin{array}{c}\mathbf{0 . 1 5 0 * *} \\
(\operatorname{lag} 2)\end{array}$ & & & & & & \\
\hline Sleep quality & & $\begin{array}{c}-0.953^{*} \\
(\operatorname{lag} 0)\end{array}$ & - & - & - & $\begin{array}{c}0.372 \\
(\operatorname{lag} 1)\end{array}$ & $\mathbf{0 . 5 6 1 * * ( \operatorname { l a g } 0 )}$ & - \\
\hline \multirow[t]{2}{*}{ Happiness } & & $\begin{array}{c}-1.035^{*} \\
(\operatorname{lag} 2)\end{array}$ & - & $\begin{array}{l}\mathbf{0 . 6 7 1 *} \\
(\operatorname{lag} 0)\end{array}$ & $\begin{array}{l}1.200^{*} \\
(\operatorname{lag} 0)\end{array}$ & - & $1.126 *(\operatorname{lag} 0)$ & - \\
\hline & & & & $\begin{array}{l}0.390^{*} \\
(\operatorname{lag} 1)\end{array}$ & & & & \\
\hline Tiredness & & - & $\begin{array}{c}-0.475^{*} \\
(\operatorname{lag} 0)\end{array}$ & - & - & - & - & - \\
\hline \multirow[t]{2}{*}{ Stress } & & $\begin{array}{l}1.090^{*} \\
(\operatorname{lag} 0)\end{array}$ & - & $\begin{array}{l}\mathbf{0 . 6 5 5 ^ { * }} \\
(\operatorname{lag} 0)\end{array}$ & $\begin{array}{l}-0.282 \\
(\operatorname{lag} 1)\end{array}$ & - & - & $1.511 * *(\operatorname{lag} 0)$ \\
\hline & & & & $\begin{array}{l}\mathbf{0 . 3 4 8 ^ { * }} \\
(\operatorname{lag} 1)\end{array}$ & & & & \\
\hline Time pressure & & - & - & - & - & - & $\mathbf{0 . 8 8 9 * * *}(\operatorname{lag} 0)$ & - \\
\hline Pain & & $1.295(\operatorname{lag} 0)$ & - & - & - & - & - & - \\
\hline \multirow[t]{2}{*}{ PA intention } & & - & - & $\begin{array}{c}-0.434^{*} \\
(\operatorname{lag} 0)\end{array}$ & $\begin{array}{c}\mathbf{0 . 4 5 6 * *} \text { (lag } \\
0 \text { ) }\end{array}$ & - & $1.201^{* * *}(\operatorname{lag} 0)$ & $\begin{array}{l}-0.435 \\
(\operatorname{lag} 2)\end{array}$ \\
\hline & & & & & $\begin{array}{c}0.506^{* * *} \text { (lag } \\
\text { 1) }\end{array}$ & & & \\
\hline \multirow[t]{2}{*}{ PA PBC } & & $\begin{array}{c}-\mathbf{0 . 8 0 2}^{* *} \\
(\operatorname{lag} 2)\end{array}$ & - & $\begin{array}{c}-\mathbf{0 . 7 1 2 * * *} \\
(\operatorname{lag} 0)\end{array}$ & - & - & - & - \\
\hline & & & & $\begin{array}{l}\mathbf{0 . 2 1 1 *} \\
(\operatorname{lag} 1)\end{array}$ & & & & \\
\hline PA priority & & - & - & - & $\begin{array}{c}-0.361^{*} \\
(\operatorname{lag} 1)\end{array}$ & - & - & $\begin{array}{c}-0.702^{*} \\
(\operatorname{lag} 0)\end{array}$ \\
\hline PA facilitation & & - & - & $\begin{array}{l}\mathbf{0 . 4 3 2 *} \\
(\operatorname{lag} 2)\end{array}$ & $\begin{array}{c}\mathbf{0 . 6 3 5 * * *} \\
(\operatorname{lag} 0)\end{array}$ & - & - & $\mathbf{0 . 5 4 8 *}(\operatorname{lag} 0)$ \\
\hline \multirow[t]{2}{*}{ PA conflict } & & - & $\begin{array}{c}-0.720 * * * \\
(\operatorname{lag} 0)\end{array}$ & $\begin{array}{l}\mathbf{0 . 4 4 4 ^ { * }} \\
(\operatorname{lag} 2)\end{array}$ & $\begin{array}{c}0.291 \text { * (lag } \\
\text { 1) }\end{array}$ & $\begin{array}{c}-0.683^{* * *} \\
(\operatorname{lag} 0)\end{array}$ & - & $\mathbf{0 . 4 3 6 * *}(\operatorname{lag} 1)$ \\
\hline & & & & & & $\mathbf{0 . 3 1 6 *}(\operatorname{lag} 1)$ & & \\
\hline \multirow[t]{2}{*}{ PA personalised } & & $\begin{array}{c}-1.051^{*} \\
(\operatorname{lag} 0)\end{array}$ & - & - & $\begin{array}{c}-0.263^{*} \\
(\operatorname{lag} 0)\end{array}$ & $\begin{array}{c}-\mathbf{0 . 4 4 2} \mathbf{2}^{* * * *} \\
\quad(\operatorname{lag} 0)\end{array}$ & - & $\begin{array}{c}-0.388^{* *} \\
(\operatorname{lag} 1)\end{array}$ \\
\hline & & $\begin{array}{l}1.086^{*} \\
(\operatorname{lag} 2)\end{array}$ & & & & & & $\begin{array}{c}-0.383^{* *} \\
(\operatorname{lag} 2)\end{array}$ \\
\hline PA bouts ${ }^{\text {prior } 2 \mathrm{~h}}$ & & 0.042 & $-0.063^{* *}$ & $-0.039 *$ & -0.016 & $-0.050^{*}$ & 0.019 & -0.053 \\
\hline PA bouts per day & & 0.007 (lag 1) & $-0.009(\operatorname{lag} 1)$ & $0.000(\operatorname{lag} 1)$ & $0.002(\operatorname{lag} 1)$ & $\mathbf{0 . 0 2 1} \mathbf{1}^{*}(\operatorname{lag} 1)$ & $-0.016(\operatorname{lag} 1)$ & 0.018 (lag 0) \\
\hline
\end{tabular}


Table 5 Overview table showing multivariable associations between predictor variables and PA bouts for all participants (Continued)

\begin{tabular}{|c|c|c|c|c|c|c|c|c|}
\hline & & Participant 1 & Participant 2 & Participant 3 & Participant 4 & Participant 5 & Participant 6 & Participant 7 \\
\hline & & $-0.002(\operatorname{lag} 2)$ & $\mathbf{0 . 0 1 3 *}(\operatorname{lag} 2)$ & $-0.004(\operatorname{lag} 2)$ & 0.004 (lag 2) & $0.003(\operatorname{lag} 2)$ & $-0.015(\operatorname{lag} 2)$ & $0.013(\operatorname{lag} 1)$ \\
\hline Interaction effects & & & & & & & & - \\
\hline $\begin{array}{l}\text { Retirement*Time } \\
\text { (study day) }\end{array}$ & & - & - & - & - & - & - & $-0.018^{* *}$ \\
\hline $\begin{array}{l}\text { Retirement*Day of } \\
\text { week }\end{array}$ & & - & - & - & $-0.291 *$ & - & - & - \\
\hline \multicolumn{9}{|l|}{$\begin{array}{l}\text { Retirement*Period of } \\
\text { day }^{d}\end{array}$} \\
\hline & $\begin{array}{l}\text { Pre- } \\
\text { retirement } \\
\text { morning }\end{array}$ & & - & & & - & - & - \\
\hline & $\begin{array}{l}\text { Pre- } \\
\text { retirement } \\
\text { evening }\end{array}$ & $0.741^{* *}$ & - & $0.291^{* *}$ & $0.781^{* * *}$ & - & - & - \\
\hline & $\begin{array}{l}\text { Post- } \\
\text { retirement } \\
\text { morning }\end{array}$ & & - & & & - & - & - \\
\hline & $\begin{array}{l}\text { Post- } \\
\text { retirement } \\
\text { afternoon }\end{array}$ & -0.313 & - & 0.018 & $-0.250^{*}$ & - & - & - \\
\hline & $\begin{array}{l}\text { Post- } \\
\text { retirement } \\
\text { evening }\end{array}$ & & - & & & - & - & - \\
\hline $\begin{array}{l}\text { Retirement*Sleep } \\
\text { quality }\end{array}$ & & $1.178^{*}$ & $0.840^{* *}$ & - & - & - & - & - \\
\hline Retirement*Happiness & & - & 0.556 & $-0.855^{*}$ & -1.368 & - & - & - \\
\hline Retirement*Tiredness & & - & - & - & - & - & $-0.539^{*}$ & - \\
\hline Retirement*Stress & & $-1.777^{* *}$ & - & $-0.776^{*}$ & - & - & - & $-1.600^{* *}$ \\
\hline $\begin{array}{l}\text { Retirement*PA } \\
\text { intention }\end{array}$ & & - & - & $0.949^{* *}$ & - & - & $-1.582^{* * *}$ & - \\
\hline Retirement*PA PBC & & - & $-0.394^{*}$ & $0.779 * *$ & - & - & - & $0.480^{*}$ \\
\hline $\begin{array}{l}\text { Retirement*PA } \\
\text { facilitation }\end{array}$ & & 0.821 & - & - & - & - & $0.680^{*}$ & - \\
\hline $\begin{array}{l}\text { Retirement*PA } \\
\text { conflict }\end{array}$ & & - & - & - & - & - & $0.603^{*}$ & $-0.597^{* *}$ \\
\hline
\end{tabular}

${ }^{*}=p<0.05 ;{ }^{* *}=p<0.01 ;{ }^{* * *} p<0.001$

${ }^{\text {a }}$ Reference category: pre-retirement

${ }^{\text {b }}$ Reference category: work day

'Reference category: afternoon

${ }^{\mathrm{d}}$ Reference category: afternoon pre-retirement

time beyond this period. This may explain why previous studies, which have measured PA from at least 6 months up to several years post-retirement [e.g. 9] have found changes in PA. Furthermore, most of the previous studies in this area have measured changes in PA via global questionnaires that involved retrospectively selfreporting PA over long periods of time. In contrast, this study used objective methods to measure day-to-day PA changes and focused specifically on short bouts of PA which have been linked to important health benefits [1] Theories about how individuals adjust to retirement may provide insight into the heterogeneity of PA levels and determinants during the retirement transition. According to Atchley [34] individuals can enter one of three potential phases after leaving work: immediate retirement (i.e. a routine is established very quickly after retirement), the honeymoon phase (where individuals seek opportunities to adopt new activities and/or travel), and rest and relaxation (a period of rest after a busy career). Individuals entering retirement may experience one or more of these stages and the order in which they experience them may vary between individuals [34]. These 
different phases may have differential effects on PA levels and determinants after retirement [15].

This study identified the time of day as a predictor of PA. For the majority of the participants, there was significantly more PA bouts performed in the morning and fewer in the evening. This is consistent with previous research which has demonstrated that older adults engage in less PA in the evening [35]. A number of evidenceand theory-based PA determinants were measured as possible predictors of PA. There were no consistent predictors of PA across all individuals and this conflicts with evidence from group-based studies. For example, evidence from a large body of group-based studies suggests that intention and PBC are important determinants of PA behaviour [36]. However, this study found that these constructs do not predict the PA of all individuals. Previous studies using n-of- 1 methods to identify intra-individual predictors of PA have also shown that group-based predictors of PA may not apply to individuals $[24,25]$. Although there was no single variable that predicted PA for all participants in the study, the most consistent determinants of PA across participants were happiness, PA conflict and the personalised questionnaire items (which were related to the influence of other people for six of the seven participants). Mood has been identified as a predictor of PA in a number of studies [19]. Furthermore, the PA behaviour, attitude and supportive nature of a spouse is known to play an important role for PA behaviour in retirement [37].

The findings show that the relationship between PA and predictors may change pre- to post-retirement, despite no significant changes to the amount of PA bouts performed. This supports the view that the retirement transition may represent a 'window' of opportunity or 'teachable moment', when older adults may be prepared to change their PA in response to the reduction of common barriers to PA such as time availability, tiredness, stress and lack of motivation during this period [15].

\section{Strengths and limitations}

This study is the first of its kind to use an n-of- 1 natural experimental design to understand changes in PA over time during the retirement transition. A major strength of this study is the use of objective measurement of PA and the use of EMA [38, 39]. The majority of existing studies exploring PA change after retirement have used self-reported measures of PA [11]. EMA involved realtime sampling of cognitions and affect in the participant's natural environment. This limits reliance on retrospective memory processes that can be biased by mood and situational factors [39]. This study is the first to apply dynamic regression modelling to evaluate changes in an individual's health behaviour over time. The majority of $\mathrm{n}$-of-1 studies conducted in health behaviour research have used visual analysis to evaluate $n$-of- 1 data [23], which does not account for existing trends or autocorrelation within the data and can bias interpretations [40]. Dynamic modelling adjusts for autocorrelation by conditioning on the past. Unlike conventional autoregressive models, which only include the previous response directly in the model, dynamic modelling allows selection of the best function of the past. The appropriateness of the dynamic model, including the interpretation of the coefficients for the lagged variables, depends on some statistical assumptions [41]. Firstly, it is assumed that the effect of the past is captured through the exogenous, endogenous and dynamic covariates described. It is also assumed that the dynamics do not change over time and that the dynamic covariates do not lie on the causal pathways between the exogenous/ endogenous covariates and the outcome. Finally, there was minimal missing accelerometer and questionnaire data. Reasons for high levels of compliance with the study procedures may be related to the fact that some aspects of the study design were personalised to each participant's preferences and interests.

Some limitations are acknowledged. Due to the use of a natural experimental design involving a pre- and postretirement phase, it is not known whether the observed PA changes for participants 4 and 7 were the result of retirement or another external factor occurring simultaneously [40]. Identified changes in PA and determinants after retirement may be related to other situational or seasonal factors. Using fixed-schedule EMA prompts may have encouraged changes in cognitions and behaviour around the time of the prompt due to participant expectation [42]. A simple imputation rule was used to impute missing questionnaire data and no imputation was carried out for missing accelerometer data. Imputing missing time series data can be problematic due to potential autocorrelation within the data. However, the minimal amount of missing data did not warrant the use of complex multiple imputation procedures [43].

\section{Implications for future research and practice}

Future research should consider long-term objective measurement of PA to identify whether PA patterns remain stable or change over time beyond the retirement transition period. Older adults engage in a high level of sedentary behaviour, an independent health risk factor that can co-occur alongside high levels of PA [44]. Longitudinal group-based studies have shown that levels of sedentary behaviour can change after retirement [e.g. 6] but future research should explore whether group-level findings apply to individuals [45]. Two participants demonstrated a statistically significant change in PA post- 
retirement. The clinical significance of these findings should be considered.

There is significant diversity between individuals concerning why and when they retire, and a number of possible PA trajectories after retirement. Therefore, a 'onesize-fits-all' approach to intervention development is not appropriate and may explain why previous interventions that have specifically targeted retirees have not been successful $[46,47]$. To account for the unique nature of retirement the most effective strategies to change health behaviours such as PA may be those that are highly personalised and meet the needs, preferences, roles and goals that individuals have when entering the retirement transition [15]. N-of-1 methods could be used in clinical practice as a tool for developing personalised interventions that target the unique determinants of PA. For example, sleep quantity was identified as an important predictor of PA bouts for participant 1 during an observational phase; therefore, this participant may benefit from an intervention which targets sleep alongside PA. Effective interventions may be those delivered before retirement but with the ability to adapt over time [48] to account for unique changes in PA determinants during the retirement transition.

\section{Conclusion}

We found there to be a statistically significant change in PA bouts for two individuals during the retirement transition. PA determinants varied considerably between individuals and for some individuals the predictors changed pre- to post-retirement. N-of-1 methods can identify intra-individual PA trajectories and determinants over time. $\mathrm{N}$-of- 1 methods can be used as a tool to aid the development of personalised PA interventions for older adults in the retirement transition.

\section{Additional files}

Additional file 1: Daily questionnaire items. (DOCX $15 \mathrm{~kb}$ )

Additional file 2: 'Awake' wear and non-wear hours using accelerometer data. (DOCX $16 \mathrm{~kb}$ )

Additional file 3: Overview tables showing multivariate associations between explanatory variables and PA bouts for each participant. (DOCX $48 \mathrm{~kb})$

\section{Abbreviations}

PA: Physical activity

\section{Acknowledgements}

FFS is funded by Fuse, the UK Clinical Research Collaboration Centre for Translational Research in Public Health. MW is a member of the Centre for Diet and Activity Research (CEDAR). Both Fuse and CEDAR are UK Clinical Research Collaboration (UKCRC) Public Health Research Centres of Excellence. Funding from the British Heart Foundation, Cancer Research UK, Economic and Social Research Council, Medical Research Council, the National Institute for Health Research, and the Wellcome Trust under the auspices of the UKCRC, is gratefully acknowledged. We wish to thank
Professor Derek Johnston and Dr. Peter Tennant for their helpful insights into the challenges related to n-of-1 data and their comments on earlier drafts of the manuscript.

\section{Funding}

This work was part of the LiveWell programme. LiveWell was supported by the Lifelong Health and Wellbeing initiative (LLHW), under grant number G0900686. The LLHW initiative is a funding collaboration between the UK Research Councils and Health Departments. The funding partners are: Biotechnology and Biological Sciences Research Council, Engineering and Physical Sciences Research Council, Economic and Social Research Council, Medical Research Council, Chief Scientist Office of the Scottish Government Health Directorates, National Institute for Health Research/The Department of Health, The Health and Social Care Research \& Development of the Public Health Agency (Northern Ireland), and Wales Office of Research and Development for Health and Social Care, Welsh Assembly Government.

\section{Availability of data and materials}

The datasets used and/or analysed during the current study are available from the corresponding author on reasonable request.

\section{Author's contributions}

SM, FFS, MW and NO conceived and designed the study. SM carried out the data collection and wrote the first draft of the manuscript. AG wrote the algorithm for processing the PA data. RV and SM carried out the analysis. All authors contributed to the interpretation of the analysis. All authors edited later drafts, read and approved the final manuscript.

Ethics approval and consent to participate

The study was approved by Newcastle University's Medical Sciences Ethics Committee (00630_1/2013).

Consent for publication Not applicable.

\section{Competing interests}

The authors declare that they have no competing interests.

\section{Publisher's Note}

Springer Nature remains neutral with regard to jurisdictional claims in published maps and institutional affiliations.

\section{Author details}

${ }^{1}$ Institute of Health \& Society, Newcastle University, Baddiley-Clark Building, Richardson Road, Newcastle upon Tyne NE2 4AX, UK. '2Department of Computer and Information Science, Northumbria University, Newcastle upon Tyne NE2 1XE, UK. ${ }^{3}$ MRC Epidemiology Unit, University of Cambridge School of Clinical Medicine, Box 285 Institute of Metabolic Science, Cambridge Biomedical Campus, Cambridge CB2 OQQ, UK. ${ }^{4}$ Fuse, UKCRC Centre for Translational Research in Public Health, Newcastle University, Newcastle uponTyne NE2 4AX, UK.

Received: 29 June 2017 Accepted: 27 November 2017

Published online: 08 December 2017

\section{References}

1. World Health Organization: Global recommendations on physical activity for health. 2010.

2. Scholes S, Mindell J. Health Survey for England 2012. Chapter 2: Physical activity in adults. London: The Health and Social Care Information Centre. p. 2013.

3. Allender S, Hutchinson L, Foster C. Life-change events and participation in physical activity: a systematic review. Health Promot Int. 2008;23:160-72.

4. Lara J, O'Brien N, Godfrey A, Heaven B, Evans EH, Lloyd S, Moffatt S, Moynihan PJ, Meyer TD, Rochester $L$, et al. Pilot randomised controlled trial of a web-based intervention to promote healthy eating, physical activity and meaningful social connections compared with usual care control in people of retirement age recruited from workplaces. PLoS One. 2016;11: e0159703.

5. Koeneman MA, Chinapaw MJ, Verheijden MW, van Tilburg TG, Visser M, Deeg DJ, Hopman-Rock M. Do major life events influence physical activity 
among older adults: the longitudinal aging study Amsterdam. Int J Behav Nutr Phys Act. 2012;9:147.

6. Touvier M, Bertrais S, Charreire H, Vergnaud AC, Hercberg S, Oppert JM. Changes in leisure-time physical activity and sedentary behaviour at retirement: a prospective study in middle-aged French subjects. Int I Behav Nutr Phys Act. 2010;7

7. Evenson KR, Rosamond WD, Cai JW, Diez-Roux AV, Brancati FL. Atherosclerosis risk in communities study investigators: influence of retirement on leisure-time physical activity - the atherosclerosis risk in communities study. Am J Epidemiol. 2002;155:692-9.

8. Berger U, Der G, Mutrie N, Hannah MK. The impact of retirement on physical activity. Ageing Soc. 2005;25:181-95.

9. Slingerland AS, van Lenthe FJ, Jukema JW, Kamphuis CBM, Looman C, Giskes K, Huisman M, Narayan KMV, Mackenbach JP, Brug J. Aging, retirement, and changes in physical activity: prospective cohort findings from the GLOBE study. Am J Epidemiol. 2007;165:1356-63.

10. Chung S, Domino ME, Stearns SC, Popkin BM. Retirement and physical activity: analyses by occupation and wealth. Am J Prev Med. 2009;36:422-8.

11. Barnett I, van Sluijs EM, Ogilvie D. Physical activity and transitioning to retirement: a systematic review. Am J Prev Med. 2012;43:329-36.

12. Van Dyck D, Cardon G, Deforche B, De Bourdeaudhuij I. The contribution of former work-related activity levels to predict physical activity and sedentary time during early retirement: moderating role of educational level and physical functioning. PLoS One. 2015;10

13. Barnett I, Guell C, Ogilvie D. The experience of physical activity and the transition to retirement: a systematic review and integrative synthesis of qualitative and quantitative evidence. Int J Behav Nutr Phys Act. 2012;9:97.

14. Stenholm S, Pulakka A, Kawachi I, Oksanen T, Halonen Jl, Aalto V, Kivimaki $\mathrm{M}$, Vahtera J. Changes in physical activity during transition to retirement: a cohort study. Int I Behav Nutr Phys Act. 2016;13

15. McDonald S, O'Brien N, White M, Sniehotta FF. Changes in physical activity during the retirement transition: a theory-based, qualitative interview study. Int J Behav Nutr Phys Act. 2015;12:25.

16. Midanik LT, Soghikian K, Ransom LJ, Tekawa IS. The effect of retirement on mental health and health behaviors: the kaiser permanente retirement study. J Gerontol B Psychol Sci Soc Sci. 1995:50:S59-61.

17. Vahtera J, Westerlund H, Hall M, Sjosten N, Kivimaki M, Sal OP, Ferrie JE, Jokela M, Pentti J, Singh-Manoux A, et al. Effect of retirement on sleep disturbances: the GAZEL prospective cohort study. Sleep. 2009;32:1459-66.

18. Westerlund H, Vahtera J, Ferrie JE, Singh-Manoux A, Pentti J, Melchior M, Leineweber C, Jokela M, Siegrist J, Goldberg M, et al. Effect of retirement on major chronic conditions and fatigue: French GAZEL occupational cohort study. Br Med J. 2010;341:c6149.

19. Trost SG, Owen N, Bauman AE, Sallis JF, Brown W. Correlates of adults' participation in physical activity: review and update. Med Sci Sports Exerc. 2002;34:1996-2001.

20. Van Dyck D, Cardon G, De Bourdeaudhuij I. Longitudinal changes in physical activity and sedentary time in adults around retirement age: what is the moderating role of retirement status, gender and educational level? BMC Public Health. 2016;16:1125.

21. Oshio T, Kan M. The dynamic impact of retirement on health: evidence froma nationwide ten-year panel survey in Japan. Prev Med. 2017;100: 287-93.

22. McDonald S, Araujo-Soares V, Sniehotta FF. N-of-1 randomised controlled trials in health psychology and behavioural medicine. Psychol Health. 2016; 31:331-3.

23. McDonald S, Quinn F, Vieira R, O'Brien N, White M, Johnston DW, Sniehotta FF. The state of the art and future opportunities for using longitudinal n-of1 methods in health behaviour research: a systematic literature overview. Health Psychol Rev. 2017;11:307-23.

24. Hobbs N, Dixon D, Johnston M, Howie K. Can the theory of planned behaviour predict the physical activity behaviour of individuals? Psychol Health. 2013;28:234-49.

25. Quinn F, Johnston M, Johnston DW. Testing an integrated behavioural and biomedical model of disability in n-of-1 studies with chronic pain. Psychol Health. 2013;28:1391-406.

26. The English indices of deprivation 2015 [https://www.gov.uk/government/ statistics/english-indices-of-deprivation-2015].

27. Wareham NJ, Jakes RW, Rennie KL, Mitchell J, Hennings S, Day NE. Validity and repeatability of the EPIC-Norfolk physical activity questionnaire. Int Epidemiol. 2002;31:168-74.
28. Presseau J, Tait RI, Johnston DW, Francis JJ, Sniehotta FF. Goal conflict and goal facilitation as predictors of daily accelerometer-assessed physical activity. Health Psychol. 2013;32:1179-87.

29. Hickey A, Newham J, Slawinska MM, Kwasnicka D, McDonald S, Del Din S, Sniehotta FF, Davis PA, Godfrey A. Estimating cut points: a simple method for new wearables. Maturitas. 2016;83:78-82.

30. Esliger DW, Rowlands AV, Hurst TL, Catt M, Murray P, Eston RG. Validation of the GENEA accelerometer. Med Sci Sports Exerc. 2011;43:1085-93.

31. Schmid CH. Marginal and dynamic regression models for longitudinal data. Stat Med. 2001;20:3295-311.

32. Vieira R, McDonald S, Araujo-Soares V, Sniehotta FF, Henderson R. Dynamic modelling of $n$-of-1 data: powerful and flexible data analytics applied to individualised studies. Health Psychol Rev. 2017;11:222-34.

33. Hosmer DW, Lemesbow S. Goodness of fit tests for the multiple logistic regression model. Commun Stat Theory Methods. 1980;9:1043-69.

34. Atchley RC. Retirement and leisure participation: continuity or crisis? The Gerontologist. 1971;11:13-7.

35. Harvey JA, Chastin SF, Skelton DA. How sedentary are older people? A systematic review of the amount of sedentary behavior. J Aging Phys Act. 2015;23:471-87.

36. McEachan RRC, Conner M, Taylor NJ, Lawton RJ. Prospective prediction of health-related behaviours with the theory of planned behaviour: a metaanalysis. Health Psychol Rev. 2011;5:97-144.

37. Barnett I, Guell C, Ogilvie D. How do couples influence each other's physical activity behaviours in retirement? An exploratory qualitative study. BMC Public Health. 2013:13:1197.

38. Kowalski K, Rhodes R, Naylor PJ, Tuokko H, MacDonald S. Direct and indirect measurement of physical activity in older adults: a systematic review of the literature. Int J Behav Nutri Phys Act. 2012;9:148.

39. Shiffman S, Stone AA, Hufford MR. Ecological momentary assessment. Annu Rev Clin Psychol. 2008;4:1-32.

40. Kazdin AE. Single-case research designs: methods for clinical and applied settings. 2nd ed. New York: Oxford University Press; 2011.

41. Vieira RV, McDonald S, Araujo-Soares V, Sniehotta FF, Henderson R. Dynamic modelling of n-of-1 data: powerful and flexible data analytics applied to individualised studies. Health Psychol Rev. 2017:1-32.

42. Bolger $N$, Laurenceau J-P. Intensive longitudinal methods: an introduction to diary and experience sampling research. New York, NY: Guilford Press; 2013.

43. Honaker J, King G. What to do about missing values in time-series crosssection data. Am J Polit Sci. 2010;54:561-81.

44. Chastin SF, Buck C, Freiberger E, Murphy M, Brug J, Cardon G, O'Donoghue G, Pigeot I, Oppert JM. consortium D: systematic literature review of determinants of sedentary behaviour in older adults: a DEDIPAC study. Int J Behav Nutri Phys Act. 2015;12:127.

45. Sprod J, Ferrar K, Olds T, Maher C. Changes in sedentary behaviours across the retirement transition: a systematic review. Age Ageing. 2015;44:918-25.

46. Hobbs N, Godfrey A, Lara J, Errington L, Meyer TD, Rochester L, White M, Mathers JC, Sniehotta FF. Are behavioral interventions effective in increasing physical activity at 12 to 36 months in adults aged 55 to 70 years? A systematic review and meta-analysis. BMC Med. 2013;11:75.

47. Opdenacker J, Delecluse C, Boen F. A 2-year follow-up of a lifestyle physical activity versus a structured exercise intervention in older adults. J Am Geriatr Soc. 2011;59:1602-11.

48. Almirall D, Nahum-Shani I, Sherwood NE, Murphy SA. Introduction to SMART designs for the development of adaptive interventions: with application to weight loss research. Transl Behav Med. 2014:4:260-74. 